\title{
What do healthcare professionals want to know about intestinal failure and home parenteral nutrition?
}

\author{
K. Farrer ${ }^{1}$ and A. Culkin ${ }^{2}$ \\ ${ }^{1}$ Intestinal Failure Unit, Salford Royal NHS Foundation Trust, Manchester M6 8HD, UK and ${ }^{2}$ Intestinal Failure Unit, \\ St Marks Hospital, Harrow, London HAl 3UJ, UK
}

In England there are two designated national centres for the management of acute intestinal failure (IF). Patients presenting with IF are relatively rare in the UK, and the management is complex. In addition there are 600 patients on home parenteral nutrition (HPN) of which over half are cared for by the two national centres. Knowledge and confidence to treat patients from a dietetic perspective can be limited.

Both centres have a dietitian as part of their nutrition team. They regularly receive queries from colleagues asking for dietetic advice to manage patients locally. The dietitians wished to establish the gaps in professional knowledge in order to identify future training needs.

A proforma was developed to record queries received from health care professionals working outside their organisations. This included details of the discipline, hospital, patient diagnosis and past medical history, relevant anatomy, nutritional and biochemical data plus the current route of artificial nutrition. The reason for the contact was recorded, the advice given and the length of time spent discussing the query.

Over a 12 month period the two dietitians received ninety-five contacts; ninety one $(95.8 \%)$ from dietitians, two (2.2\%) from nutrition nurses $(1 \%)$, one from a surgical registrar $(1 \%)$ and one from a pharmacist. Nineteen $(20 \%)$ of the queries were from overseas including South Africa, Finland, New Zealand and Ireland. The results were recorded under themes as shown in the Table. The total time spent advising other professionals was calculated as $31.7 \mathrm{~h}$.

\begin{tabular}{lccc}
\hline Theme & $\begin{array}{c}\text { Total number } \\
\text { of queries }\end{array}$ & $\begin{array}{c}\text { St Marks } \\
\text { Hospital }\end{array}$ & $\begin{array}{c}\text { Salford Royal NHS } \\
\text { Foundation Hospital }\end{array}$ \\
\hline $\begin{array}{l}\text { Management of short bowel } \\
\text { syndrome }\end{array}$ & 37 & 26 & 11 \\
$\begin{array}{c}\text { Fistuloclysis / Distal feeding and } \\
\text { other enteral feeding in IF }\end{array}$ & 25 & 1 & 24 \\
HPN - indications and regimens & 24 & 17 & 7 \\
$\begin{array}{l}\text { HPN - monitoring, vitamins + } \\
\text { minerals, (policies and protocols) }\end{array}$ & 13 & 9 & 4 \\
$\begin{array}{l}\text { Management of other } \\
\text { causes of IF }\end{array}$ & 5 & 4 & 1 \\
\hline
\end{tabular}

It is clear that more post graduate education for dietitians is required on the management of IF and HPN. The time spent advising other healthcare professions has resource implications for staff working in specialist centres. 